San Jose State University

SJSU ScholarWorks

Master's Theses

Master's Theses and Graduate Research

Spring 2011

\title{
The Impact of Instructor-Provided Lecture Notes and Learning Interventions on Student Note Taking and Generative Processing
}

Karen Lynn Gee

San Jose State University

Follow this and additional works at: https://scholarworks.sjsu.edu/etd_theses

\section{Recommended Citation}

Gee, Karen Lynn, "The Impact of Instructor-Provided Lecture Notes and Learning Interventions on Student Note Taking and Generative Processing" (2011). Master's Theses. 3927.

DOI: https://doi.org/10.31979/etd.xump-ezj3

https://scholarworks.sjsu.edu/etd_theses/3927

This Thesis is brought to you for free and open access by the Master's Theses and Graduate Research at SJSU ScholarWorks. It has been accepted for inclusion in Master's Theses by an authorized administrator of SJSU ScholarWorks. For more information, please contact scholarworks@sjsu.edu. 
THE IMPACT OF INSTRUCTOR-PROVIDED LECTURE NOTES AND LEARNING INTERVENTIONS ON STUDENT NOTE TAKING AND GENERATIVE PROCESSING

\author{
A Thesis \\ Presented to \\ The Faculty of the Department of Psychology \\ San José State University \\ In Partial Fulfillment \\ of the Requirements for the Degree \\ Master of Arts
}

by

Karen L. Gee

May 2011 
(C) 2011

Karen L. Gee

ALL RIGHTS RESERVED 
The Designated Thesis Committee Approves the Thesis Titled

THE IMPACT OF INSTRUCTOR-PROVIDED LECTURE NOTES AND LEARNING INTERVENTIONS ON STUDENT NOTE TAKING AND GENERATIVE PROCESSING

\author{
by \\ Karen L. Gee \\ APPROVED FOR THE DEPARTMENT OF PSYCHOLOGY \\ SAN JOSE STATE UNIVERSITY \\ May 2011 \\ Dr. Ronald F. Rogers \\ Department of Psychology \\ Dr. Mark K. Felton \\ Department of Secondary Education \\ Dr. Sean Laraway \\ Department of Psychology
}




\begin{abstract}
THE IMPACT OF INSTRUCTOR-PROVIDED LECTURE NOTES AND LEARNING INTERVENTIONS ON STUDENT NOTE TAKING AND GENERATIVE PROCESSING

by Karen L. Gee

While the review (memory storage) function of student lecture notes is well established, research findings on the learning benefits of actually taking these notes (memory encoding) has been mixed. The current study provided all students with a complete content outline for use in studying, so the effects of taking personal notes could be isolated. Students who received the complete outline before the lecture took significantly fewer personal notes than did students who received the outline after lecture, though both groups performed similarly on factual and application tests. Students who were directed to generate novel examples for each topic also performed better on the application test than did students who were told to reread or summarize. These findings provide mixed support for the generative theory of learning, in which activities directed at helping the learner make internal and external connections with content facilitate learning.
\end{abstract}




\section{ACKNOWLEDGEMENTS}

This master's thesis is the result of the efforts of many individuals. First, thanks are due to Dr. Frank Payne, who provided vital input on the original design of the experiment, as well as important guidance through the IRB approval process. Second, great appreciation is due to Dr. Mark Felton, whose dedication to a true demonstration of subject area mastery led to his extensive feedback on the literature review of this thesis. Third, Dr. Sean Laraway's assistance with the statistical analyses and presentation of results was extraordinarily helpful.

Most of all, Dr. Ronald Rogers must be commended for his above-and-beyond involvement in guiding this project at every stage of its development, from inception, to data collection, to preparing a manuscript consistent with all APA and SJSU guidelines. His long-term support and attention to detail are noteworthy and admirable.

Lastly, additional thanks are due to the psychology students of Foothill College, whose educational experiences provided the inspiration for this thesis, and whose future success will continue to make the study of optimal teaching strategies worth pursuing. 


\section{TABLE OF CONTENTS}

SECTION

PAGE

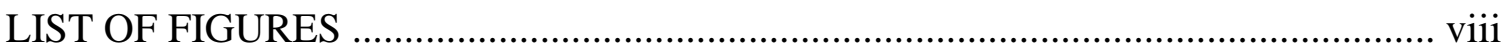

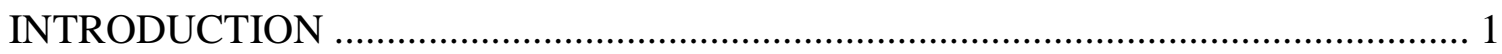

The Generative Model of Learning ............................................................. 1

Cognitive Load Theory and Learning …........................................................ 5

Reconciling the Generative Model and Cognitive Load Theory ......................... 7

The Value of Student Note Taking ............................................................ 8

The Value of Instructor-Provided Notes and Learning Interventions ................ 13

Study Aims and Predictions ................................................................. 18

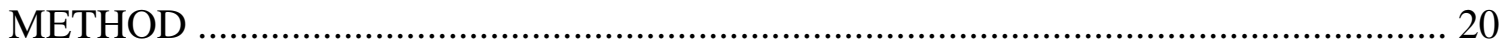

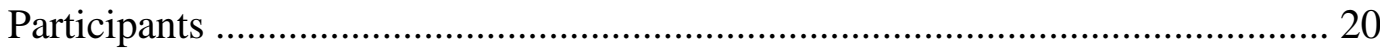

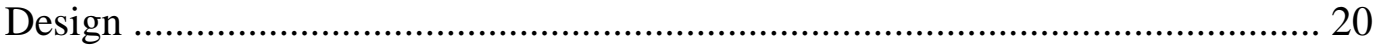

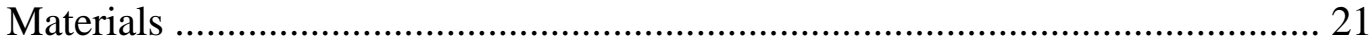

Procedure ....................................................................................... 23

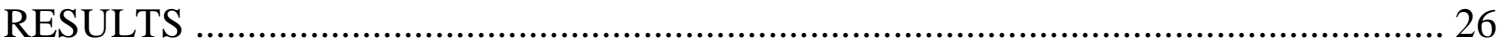

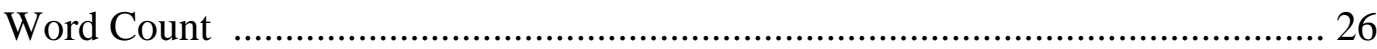

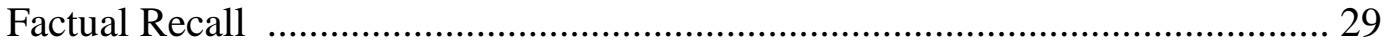

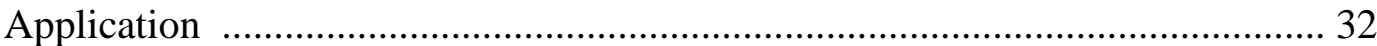

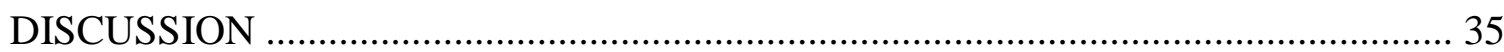

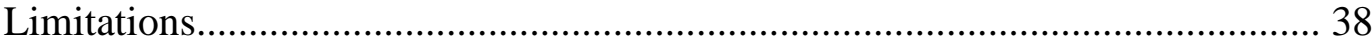

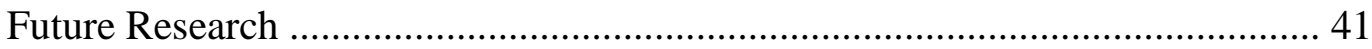




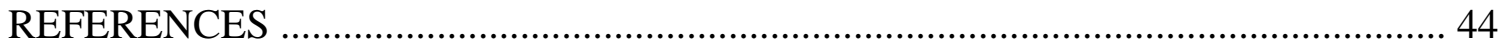

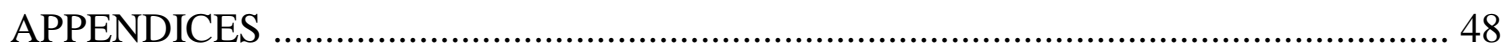

Appendix A: Lecture Transcript .......................................................... 48

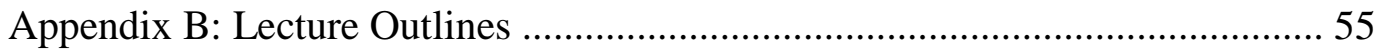

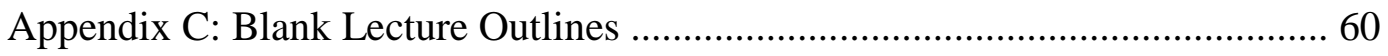

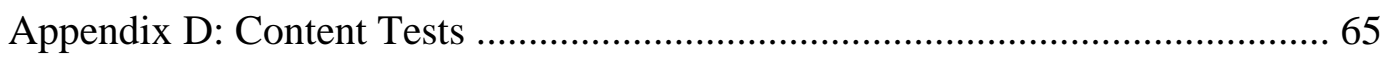

Appendix E: Post-Experiment Survey …..................................................... 70 


\section{LIST OF FIGURES}

FIGURE

PAGE

1. Mean words written in personal notes as a function of timing of instructorprovided notes and assigned study technique

2. Mean number of correct answers on factual recall test items as a function of timing of instructor-provided notes and assigned study technique

3. Mean number of correct answers on application test items as a function of timing of instructor-provided notes and assigned study technique 


\section{Introduction}

According to the National Center for Educational Statistics, $83 \%$ of college and university faculty use the lecture format as the primary instructional method in some or all of their classes (Wirt et al., 2001). Observational studies conducted in college classrooms representing a variety of subject areas at different levels have found that lecturing represents about $80 \%$ of class time (Fischer \& Grant, 1983; Smith, 1983; Ellner, 1983). Most students take their own notes during lecture, in part because many students (and many teachers) believe that writing down new information in this fashion helps them learn (Carrier, Williams, \& Dalgaard, 1988). The question is, does it? Does the act of taking notes during lecture facilitate learning?

Broadly speaking, there are two possible, contradictory answers to this question, each with a theoretical framework existing to support it.

\section{The Generative Model of Learning}

M. C. Wittrock (1992) wrote extensively on the generative model of learning, which is based on the idea that making connections, either among diverse parts of the material being learned (internal connections) or to one's own prior knowledge (external connections), produces greater learning. In this theory, the brain is a model builder, not merely an empty box in which incoming sensory information may be placed for storage. Instead, the brain must actively generate meaning to make sense of new experience, to create the neural networks in which knowledge resides, and to organize them in ways that facilitate easy retrieval. 
Because it assumes that the active generation of internal and external connections is vital for learning, this model implies that learners must have sufficient motivation to invest effort in making these connections, and to hold themselves accountable for constructing them. To this end, learners must perceive successful learning to be the result of their own effort, as opposed to intelligence, other individuals (such as teachers), or other external factors (Wittrock, 1990).

In addition to being motivated, the learner must be able to pay sufficient attention to the necessary content to be learned and to relevant stored memory. Attention develops gradually in children, and sustained attention in particular is a problem for many children with learning disabilities. The ability to ignore irrelevant information also develops with age and/or practice and is related to self-control strategies (Wittrock, 1990).

Successful learning, then, is a constant process of deciding the events to attend to and then reorganizing, elaborating, and re-conceptualizing information in ways that increase understanding. It is the act of creating these connections, of constructing meaning, that is thought to facilitate comprehension, not merely fitting new information into existing schemata (as advanced by schema theorists) or processing information semantically (as described by cognitive psychologists) (Wittrock, 1990). The most successful learning would be indicated by the ability to transfer newly acquired knowledge to a novel problem, requiring the learner to go beyond the surface content of the material originally presented, to be able to use it in a new situation (Wittrock, 1974). In addition, the very act of applying this knowledge in a new situation is another 
opportunity for generative processing, as even more new connections can be made through further analysis and effort.

Thus, in the generative model, successful teaching for comprehension involves guiding the learner to generate relations among concepts and between new information and prior learning. As Wittrock (1990) states, "Even when a teacher tells us an answer... we must still discover its intended meaning. Being given the answer does not necessarily aid or deter comprehension. It depends on what we do with that information, what we think about, and how we relate it to our knowledge" (p. 353). The teacher's job would be to influence the learner to think about tasks differently, to construct different meanings, to use different learning strategies, and to relate knowledge to the material to be learned (Wittrock, 1990).

Several of Wittrock's experiments demonstrate improvements in learning when students are instructed to engage in activities designed to promote the generation of new connections. For example, Doctorow, Wittrock, and Marks (1978) conducted a reading experiment in which elementary school children who were instructed to generate a sentence describing each paragraph scored higher on reading comprehension and retention than students who were provided one or two word organizers, and that these students scored higher than control students who read only the passages. In another study, college students who were provided lists of words and then asked to create hierarchies that "made sense" outperformed students who were instructed merely to copy the hierarchies they were given (Wittrock \& Carter, 1975). 
The generative model became part of a dominant trend in educational research known as constructivism, in which the learner's interpretation and processing of stimuli are the primary variables under study. Wittrock (1974) wrote, “The current welcomed shift is toward cognitivism, toward reinstating the learner, and his cognitive states and information-processing strategies, as a primary determiner of learning with understanding and long-term memory" (p. 47). The idea of treating students as passive receptacles that the teacher must fill with information fell out of favor as a student-centered paradigm emerged.

In the field of education, constructivism is still a widely accepted theory of learning (Kintsch, 2009), though many researchers remain critical of some of its applications to instructional practices (Mayer, 2004; Mayer, 2009). The major controversy comes from consistent findings that show guided instruction produces superior learning outcomes when compared to less structured learning strategies (such as discovery, problem-based, experiential, or inquiry-based learning), at least until learners have enough prior knowledge to provide "internal" guidance (Kirschner, Sweller, \& Clark, 2006). For example, in contrast to predictions of generative theory, Stull and Mayer (2007) found that providing students graphic organizers for a scientific text led to deeper processing (indicated by improved transfer performance) compared to asking students to create graphic organizers as they read, even though the groups did not differ significantly on a basic retention test. Given these results, the next relevant question is what other effects, in addition to generative processing, such activities may have on the learner. 


\section{Cognitive Load Theory and Learning}

Cognitive load theory may provide a way to reconcile the apparent paradox between the necessity of building personal connections with learning content, and research demonstrating that unstructured learner-driven education is less effective than direct instruction. The central issue in cognitive load theory is processing capacity: the learner has a task to master, but only a limited amount of working memory to devote to the task. Any given learning task has three different types of cognitive load requiring attention from the learner, the sum of which determine the difficulty of the task (Paas, Renkl, \& Sweller, 2003).

Intrinsic cognitive load refers to complexity that is an inherent aspect of the learning task. If the elements of the task are highly interdependent, then the task cannot be simplified without removing individual elements that are essential to comprehension, and no modifications to the instruction itself can change the complexity inherent to task to be learned. Time and familiarity will eventually enable learned concepts to be shifted from working memory into the effectively limitless space of long-term memory, to be retrieved with little cognitive load when needed. This reduces the strain on working memory; enabling earlier-ignored content elements to be integrated back in so complete understanding becomes possible (Paas et al., 2003).

In addition to complexity inherent to the task, the manner in which information is presented to learners, and the learning activities required of them, can also impose a cognitive load. When these activities impose their own mental strain on the learner in a way that interferes with concept acquisition, it is referred to as extraneous or ineffective 
cognitive load. For example, unstructured learning activities may cause students to expend a lot of mental energy simply figuring out what to do, leaving less processing capacity available to learn the target concepts. This problem is important primarily when intrinsic cognitive load is high, already pushing the learner toward the limits of his or her working memory capacity before extraneous cognitive load is added in (Paas et al., 2003).

Finally, germane or effective cognitive load is determined by how the instructional designer structures information presentation and learning activities to involve students in concept acquisition, as opposed to activities irrelevant to learning. Activity on the part of the learner that contributes to shifting concepts from working memory into long-term memory facilitates learning. Effort and motivation, if relevant to concept acquisition and automation, can increase germane cognitive load, in way that enhances learning (Paas et al., 2003).

Research on instructional design has succeeded in developing scaffolding techniques (providing initially sufficient, then progressively fading, support for the learner) based on cognitive load theory. For example, sequencing components of the task from simple to complex, helping learners develop routines for performing consistent task components, and presenting task-essential information "just in time," can all help reduce cognitive load at critical moments during the learning process (van Merriënboer, Kirschner, \& Kester, 2003). Intrinsic cognitive load gradually decreases as a learner masters components of a complex task, allowing a gradual increase in problem-solving demands without inducing cognitive overload (Renkl \& Atkinson, 2003). 


\section{Reconciling the Generative Model and Cognitive Load Theory}

To summarize, cognitive load theory posits that people only have so much processing capacity to use at any given moment (Paas et al., 2003). This theory would seem to suggest that having to write notes while simultaneously trying to listen and understand the lecture could undermine learning. On the other hand, generative theory states that the learner must actively make internal (within content topics) and external (with preexisting knowledge) connections with the material being learned, and that this activity is the essential piece of what makes learning occur (Wittrock, 1992). Under this theory, taking notes should facilitate learning, because it forces students to actively construct meaning as they select and interpret ideas to write them down.

A crucial question in the current study is whether student note taking during lecture serves as extraneous (ineffective) or germane (effective) cognitive load. Do the activities of selecting important ideas, paraphrasing them, and writing them down while the instructor is speaking enhance long-term memory formation? Or do these activities undermine learning by taxing working memory with irrelevant activity, leaving less processing capacity available for concept acquisition? The second relevant note taking question revolves around the role notes play in knowledge acquisition when the instructor is done speaking. In what ways can students use notes and note taking to maximize germane cognitive load, and minimize extraneous cognitive load?

According to the generative model, at some point in the learning process, students must build connections with novel information. If students are in a formal educational situation, such as a lecture, their ability to retain and use the content presented to them 
will depend in part on how well they can attach these concepts to each other, and to something they already know. Their ability to do this may be aided by 1) getting the information into memory in a particular way, and 2) being able to review and revisit this information to solidify memory (Di Vesta and Gray, 1972). For both of these reasons, memory encoding and memory storage, taking notes during lecture is assumed to be an important part of learning. The interesting question is whether students' notes produce germane cognitive load at the encoding phase, the storage phase, or both.

\section{The Value of Student Note Taking}

The value of the storage function of notes has been well documented. In 32 studies reported by Hartley (1983), Kiewra (1985), or both, 24 found that students who reviewed their own lecture notes had higher achievement on performance tests than those who took notes but were not permitted to review them. Eight other studies reported no differences between reviewers and nonreviewers, and no study indicated that review was harmful (Kiewra, 1991). Ryan (1982) conducted a meta-analysis including the small number of then-existing studies examining learning outcomes of note taking with later review, and found a mean unweighted effect size $(d)$ of .34. It should be noted, however, that this estimate was calculated from only 19 of 123 effect sizes in the study, since the remaining 104 effect sizes were for estimating the effects of note taking without later review. A more recent meta-analysis by Kobayashi (2006) found a mean weighted effect size of .75 comparing note taking and review groups (including 32 effect sizes) with listening or reading only, and a mean weighted effect size of .77 comparing note taking and review groups (including 72 effect sizes) with listening or reading with mental 
reviewing. These findings indicate a moderate to large positive effect of note taking and review over no note taking, and are probably more accurate than Ryan's (1982) estimate, based on the larger number of studies included.

It should be recognized that one of the challenges of interpreting the gap in performance between note taking with review over note taking (or no note taking) without review is that in many studies, the amount time on task, and thus of exposure to the material, is greater in the note taking with review condition. It is difficult to know whether the improvement in performance is truly due to the storage function of notes, or simply due to having more time, or more effective use of time, during the study period, where further encoding may take place.

Questionnaire data indicates that the majority of students take notes with the intention of reviewing them. For example, Hartley and Davies (1978) reported that $98 \%$ of American students $(n=52)$ and $84 \%$ of British students $(n=71)$ answered "yes" to the questionnaire item, "I take notes to have review material for examination" and Carrier and Newell (1984) found that $91.7 \%$ of dental hygiene students $(n=48)$ agreed to the idea, "Taking notes is important because I can review them."

In contrast, evidence for the encoding function of note taking is mixed. Several studies have compared students taking notes during a lecture with students not taking notes. In 61 studies reviewed by Hartley (1983), Kiewra (1985), or both, 35 found that note takers did better on performance tests, 23 indicated that note takers and non-note taking listeners performed comparably, and 3 reported that listening without note taking led to better performance than note taking (Kiewra, 1991). A more recent meta-analysis 
by Kobayashi (2005) found a mean weighted effect size of 0.22 across 131 independent samples in 57 studies, qualifying as small to medium magnitude according to Cohen's (1988) criteria. This is a much smaller result than the $.75-.77$ effect size found in Kobayashi's (2006) estimate of the value of note taking plus review, indicating that later review of notes adds substantially to the value of note taking.

Several studies in this area shed light on why the encoding effect of note taking seems to be limited, and why note taking during lecture may not serve a generative function. Bretzing and Kulhavy (1981) found that students tended to record verbatim notes, rather than the summaries, analogies, examples, or conclusions that would actually indicate generative processing. Such verbatim notes may actually increase external storage benefits by containing more complete information, even as they reduce encoding effects by interfering with deeper processing while the lecture is taking place (Bretzing \& Kulhavy, 1979). Kiewra and Fletcher (1984) actually directed students to record generative notes, but found that students were largely unable to do so. Kobayashi's (2005) meta-analysis uncovered this as a consistent pattern: in general, positive interventions did not enhance the benefits of note taking. Effective training in generative note taking may require more guidance and practice than is typically provided in a brief research study.

Another limitation on the encoding effect may be cognitive load, or the working memory demands required to perform a particular task. The cognitive demands of listening to the lecture, selecting important ideas, interpreting the information, and writing it down may leave little time and mental resources for generative processing. The 
distraction hypothesis, corresponding to extraneous load in cognitive load theory, suggests that taking notes reduces a learner's ability to pay attention to the lecture, particularly when the information is presented at a rapid rate (Peters, 1972). This hypothesis is in contrast to the attention hypothesis, corresponding somewhat to the idea of germane load, which states that note taking forces the learner to pay more attention to the presented material and to process it more deeply (Craik \& Lockhart, 1972).

How intrinsic, extraneous, and germane cognitive load play out for any given learner in a particular learning situation depends on a variety of factors, because cognitive load always relates to the cognitive processes of a particular person. Prior knowledge, for example, is one of the most important variables affecting the complexity of a given task for any particular learner. In the expertise reversal effect, novice learners may experience extraneous cognitive load because insufficient external guidance fails to compensate for their limited knowledge base, while expert learners may experience a different cognitive load problem as they continually waste energy checking new information against their own internal representation of the same content (Kalyuga, 2007). Clearly, the question of whether taking notes would help or hurt absorbing the material in the moment is a complex one.

The benefits of note taking, generative or otherwise, may also depend on the learning goal. The attention and distraction hypotheses assume that the relevant question is whether the learner is acquiring factual information. Generative theory assumes that additional cognitive processes are involved, such as relating material to existing knowledge. These separate types of "learning" would be tapped by different kinds of 
performance tests, which might explain some of the diversity in findings regarding the encoding function of note taking. For example, in one experiment by Peper and Mayer (1986), non-note takers excelled on near-transfer tasks (such fact retention and verbatim recognition), while note takers excelled on far-transfer tasks (such as problem solving). Kobayashi's (2005) meta-analysis detected a stronger encoding effect on recall performance measures than on recognition or higher-order performance tests.

An additional problem with past studies in this area has been the inability to isolate the encoding and storage functions of the note taking process. In many past studies, the outcome of the note taking process is confounded with differences in the completeness of these notes, meaning that students who take better notes also have better notes to review. One pair of experiments attempted to compensate for this by examining the performance of students who took notes during a lecture and were allowed to study their notes later (encoding plus storage), compared with students who observed a lecture while taking notes but were given no time to study them (encoding only), as well as a group of students who were absented from the lecture, but then given the opportunity to review notes "borrowed" from a student in the encoding-only group (storage only). This was a clever strategy for examining the storage function of note taking isolated from the encoding function. Kiewra et al. (1991) found that students who borrowed notes without attending lecture did not differ on cued recall, factual recognition, application, and synthesis than students who attended the lecture, took, and studied their own notes. Perhaps most interestingly, on the synthesis test, students in the storage-only (borrowed notes) condition significantly outperformed students in the encoding-only (took notes, no 
review) group. Kiewra, Dubois, Christensen, Kim, and Lindberg (1989) equalized the allotted time for processing by having the having the encoding group take notes on two occasions without review, the encoding-plus-storage group take notes one time and review notes the next, and the external-storage group twice review a set of borrowed notes. Still, it is difficult to tell if the comparison is fair one, because viewing a lecture forces a student to follow the content at a particular pace, limiting his or her ability to move faster or emphasize more challenging content, and studying another student's (presumably incomplete) notes also provides limited opportunity for that student to encode all relevant information in the first place. In any event, in this demonstration, encoding-plus-storage participants performed better on factual-recall and recognition tests, but not on higher-order performance.

\section{The Value of Instructor-Provided Notes and Learning Interventions}

Providing students a complete set of notes containing the main ideas and details in a lecture is likely to have consequences on student note taking and study behavior, the outcomes of which can then be analyzed. It is possible that even when instructor notes are provided as a tool for review (addressing the storage function of notes), the actual process of taking notes during lecture (addressing the encoding function) aids learning. It may provide students an opportunity to record more personally meaningful information (Van Meter, Yokoi, \& Pressley, 1994), containing more effective retrieval cues because it was encoded according to the student's own style and prior knowledge connections (Carrier \& Titus, 1981). As stated in the attention hypothesis (Frase, 1970), this may help students concentrate, or help them clarify concepts as they write them down. 
Providing instructor notes in addition to personal notes helps remove the confound of personal note quality during the review process, so that the effect of taking the notes can be examined separately.

Prior research has indicated that students, in general, are poor note takers. For example, Baker and Lombardi (1995) studied the notes of introductory psychology students, and found that most of them recorded less than $50 \%$ of lecture information relevant to the course examination. Having key concepts missing from student notes obviously reduces the value of studying from such notes. Complete instructor notes can serve not only as a guide to what is important, but also reduce the penalty for failing to record an important point during the lecture. Kiewra and his colleagues have demonstrated clearly that instructor notes, being more complete than student notes, can be very beneficial for student review (e.g., Kiewra, 1985). However, these studies have also shown that simply reviewing notes, even very complete ones, does not promote the type of generative processing (organizing information and associating it with previously acquired knowledge) that helps improve higher-level comprehension (Kiewra et al., 1989). For example, Kiewra, DuBois, Christian, and McShane (1988) found that instructor-provided outlines and matrices given to students a week after the lecture increased their performance on recall measures. Matrices (tables organized to help foster connections among different topics) also produced higher transfer performance, which required students to use the information they had learned in a novel way. However, when Kiewra and colleagues (1989) had students take their own skeletal or matrix notes, they found little or no performance difference based on note taking format for transfer and 
application measures, which are arguably the performance measures that should be most strongly associated with generative processing. Thus, while several note taking strategies have been found to enhance student recall, higher-order comprehension has been difficult to improve through instructor-guided modification of student note taking or review.

Based on Mayer's (1984) article “Aids to Text Comprehension,” Kiewra (1991) suggested three ways to improve the quality of student notes to enhance lecture learning: (a) help students select the information that is most important to learn, (b) help students make relationships among lecture ideas [internal connections], and (c) help students make relationships between lecture ideas and prior knowledge [external connections]. Students have a tendency to treat lecture content as a list of isolated ideas. Specific instructions on what to listen for, highlighting/underlining, topic sentences, and definitions may all help students select and attend to relevant information; these types of selection aids tend to boost retention of facts. Outline headings and structured note taking can help students build internal connections by showing how various concepts relate to one another, and should result in a greater synthesis of ideas. Finally, familiar models, analogies, or examples can help foster external connections, which should result in an improved ability to apply the new knowledge in different settings. Research by Tobias (1989) indicates that these kinds of interventions should be especially helpful to students with limited prior knowledge on the topic, as such students benefit greatly from substantial instructional support, while more knowledgeable students can succeed without such assistance. 
Generative study strategies, such as creating and answering one's own study questions, or summarizing lecture material, can also be effective in improving retention (King, 1992). Peper and Mayer (1986) found that taking summary notes or answering conceptual questions during breaks in the lecture produced results similar to note taking: non-note takers excelled on near-transfer tasks (such fact retention and verbatim recognition), while note takers excelled on far-transfer tasks (such as problem solving). Kobayashi's (2006) meta-analysis found that in general, researchers attempting to apply interventions to students' spontaneous note taking/reviewing have produced a modest effect (mean weighted effect size of .36), suggesting that students' students' spontaneous note taking/reviewing can still be improved through intervention. This same metaanalysis found that instructor-provided notes, such as a structured framework indicating what students should write down, enhanced the effects of note taking/reviewing even more than pre-training or verbal instructions only.

Instructors who are willing to provide lecture notes to students may wonder if doing so could impede students' generative processing during the note taking process, even as it provides them with more complete notes for review. In a study involving concept maps, Lee and Nelson (2005) found that students who learned to generate their own concept maps gained significantly higher scores on well-structured problem-solving performance (though not ill-structured problem-solving performance) than did students who studied complete maps. It is possible that having the instructor's notes may cause students to take fewer of their own notes, as was found by Morgan, Lilley, and Boreham (1988), and thus reduce their generative processing. On the other hand, Stefanou and 
Hoffman (2008) found that the more students copied directly from the instructor's PowerPoint or overhead presentation, the poorer their performance on factual recall questions (though the more they added to these notes, the better their performance on application questions). It is possible that relieving the cognitive strain of taking notes while listening to the lecture may enable students to think more deeply about the material, thus increasing their generative processing. A study of students taking their own notes before receiving notes from the instructor (without knowing in advance that they would receive them), compared to students receiving the instructor notes before lecture, could help provide an answer. This manipulation would also help determine how having complete instructor notes during lecture affects students' own note taking behavior. Do students with a complete outline of the lecture content at the start of the lecture take fewer of their own notes, or qualitatively different notes, than students who expected to have only their own notes to study and review? If the notes they take do tend to be different, is there a corresponding difference in what knowledge is successfully retained and applied? Depending on the impact on students' note taking and test performance, instructors would gain a rationale for providing instructor notes before lecture (to reduce the cognitive strain of note taking and allow students to listen more easily), or after lecture (to provide the notes for review, without eliminating any generative benefit of having students take their own notes).

It seems obvious that students who have notes to review post-lecture, as opposed to students attempting to review novel material with no external aids at all, are at a learning advantage. The current experiment is an attempt to discover whether knowing in 
advance that one has a complete set of notes at one's disposal affects personal note taking behavior, and if so, if differences in personal note taking then affect performance. The primary question is whether or not the act of taking notes during a lecture, as an activity in itself, improves learning. The advantage of having study notes after the lecture (as opposed to creating them) can be removed by providing all students with complete instructor-created notes for use while they study, regardless of what notes they took down themselves. With all student note takers on equal footing in terms of study resources, the learning benefits of taking notes can be isolated and measured.

\section{Study Aims and Predictions}

The purpose of this study can be described in terms of three goals: 1) to investigate how providing instructor notes before lecture affects students' own note taking behavior (in terms of a change in the volume of personal notes taken), 2) to see to see whether providing instructor notes at the time of encoding (i.e., during the lecture) helps or hurts students' performance on memorization or application measures, and 3) to weigh the relative importance of making internal or external connections to lecture material, using specific strategies that help encourage each.

The question of how to improve learning beyond memorization of facts is an important one. As educators today focus increasingly on comprehension as opposed to memorization, strategies that help improve this more challenging type of learning become more valuable.

The following hypotheses are based on prior research in this area: 
1. Students receiving instructor notes prior to lecture will take fewer of their own notes than will students receiving instructor notes after lecture.

2. a. All groups will perform similarly on measures of memorization, but

b. Individuals receiving instructor notes after lecture will perform better on application measures than will individuals receiving instructor notes prior to lecture.

3. On application measures, students providing real-life examples of the lecture topics will perform better than will students creating summaries of the information, and these students will outperform subjects who only reread their notes for review. 


\section{Method}

\section{Participants}

Using posted research participation sign-up sheets, 254 students were recruited from Introductory Psychology classes at San Jose State University. Of the sample recruited, 240 students successfully completed both sessions. Students were presumed to be participating for course credit. Informed consent was obtained for all students at the start of their participation in the study. Student names and university student ID numbers were recorded for the purpose of giving research participation credit. However, the research materials themselves were coded only by student-created identification numbers, which the experimenter did not connect to the students' names.

According to the survey administered upon completion of the second session, the participant sample was $61.25 \%$ female $(n=147)$ and $38.75 \%$ male $(n=93)$. Asked to indicate their year in school, 158 of the participants stated they were freshmen, 46 were sophomores, 23 were juniors, 6 were seniors, and 5 were graduate students. When asked to select their major, 30 students indicated "Psychology," 24 selected "Other Social Science, and 186 listed "Other." Asked to self-report their approximate grade point average, 38 selected the range " 3.6 to 4.0, ," 90 indicated " 3.1 to 3.5 ," 68 chose " 2.6 to 3.0," 32 selected " 2.1 to 2.5 ," 10 students marked "1.6-2.0," and no students indicated "Below 1.5." (2 other responses could not be coded).

\section{Design}

This study was a 2 x 3 between-subjects factorial design. The first independent variable was timing of instructor-provided notes, either Before Lecture (presumed to 
decrease student note taking), or After Lecture (presumed to increase student note taking). The second independent variable was study technique, with each student randomly assigned to a group for Rereading (control), Summarizing (presumed to facilitate internal connections), or Examples (presumed to facilitate external connections).

Two dependent variables, Factual Recognition (the ability to remember factual information) and Application (the ability to relate information to a novel example), were measured by the number of correct responses on a paper-and-pencil multiple-choice test. The notes that participants took during the study were also analyzed, and personal note length, measured as the number of words recorded, was included as a third dependent variable.

\section{Materials}

A 19-minute videotaped mock lecture describing five types of creativity was used as the lecture stimulus for all subjects in the study (see Appendix A). This lecture contained 1,881 words and was transmitted at a rate of approximately 100 words per minute (Kiewra et al., 1988). The five types of creativity were listed at the outset, as well as a list of the differentiating characteristics, corresponding to the subtopics listed on the student outline. Next, each type of creativity was explained in detail, following the sequence of topics and subtopics on the student outline. The video presentation contained only the speaker. No additional graphics were presented.

A complete instructor outline containing all the important main ideas and details given in the lecture was distributed to all participants, either before or after they viewed 
the videotaped lecture (see Appendix B). For each type of creativity, this outline listed the topic headings (type, definition, time demand, motivation, distinguishing characteristics, related characteristics, myths, and myths dispelled), and had all the content already filled in.

A blank outline (with topic headings only) was distributed to all participants before they viewed the lecture, for use in their own note taking. For participants in the Summarizing and Examples conditions, this outline also included a prompt and space to write a brief summary or example (depending on study technique condition) after each section of the lecture (see Appendix C).

A 48-question paper-and-pencil multiple-choice test, including 32 factual recognition questions and 16 application questions, was used to measure participants' memorization and comprehension of the lecture content (see Appendix D). The questions were generated by Kenneth Kiewra and his colleagues for use in their research on student note taking. There was no official process of validation "except to say that all of the researchers were in agreement that the items were accurate and measured the intended learning outcomes (e.g., facts or application)" (K. Kiewra, personal communication, October 4, 2010). Questions on the Factual Recognition section asked participants to indicate what type of creativity was most closely associated with certain characteristics, such as the "Ability to use past experience to solve everyday problems," or "Great risk takers," as well as questions following the format of, "Which two types of creativity involve rapid responding?" These items utilized examples and vocabulary reproduced verbatim from the lecture and notes. Questions on the Application Test asked 
participants to identify what type of creativity was being described by a situation that had not been presented earlier in the lecture or notes, such as, "Josh was a natural camper his first time out. Although he forgot his canteen and knife, he used his shoe to drink from and scaled a fish using tree bark." The lecture videotape, instructor notes, outlines, and content tests were provided by Kenneth Kiewra, of the University of Nebraska-Lincoln, and had been used in several of his previous studies on note taking (e.g. Kiewra et al., 1988; Kiewra et al., 1989).

A post-experiment survey contained questions about participants' year in school, major, and grade point average. It also asked participants how motivated they were to perform well on the test, what materials they relied on most during their study period, and if they had any prior knowledge about the types of creativity described in the lecture (see Appendix E).

\section{Procedure}

Students' participation took place during two sessions, seven days apart. Subjects scheduled their first session on a public sign-up sheet, and agreed at that session to return the following week at the same date and time.

At the first session, students were randomly assigned to an instructor notes condition (Before lecture, After lecture). Students in the Before lecture condition received instructor notes before viewing the lecture, and were given the following instructions:

You will be watching a 20-minute lecture about five different types of creativity. You have been given a handout with all the 
important main ideas and details given in the lecture. You may supplement this handout with your own notes in any way you like, including by using the blank outline provided.

Students in the After lecture condition were given the following instructions: You will be watching a 20-minute lecture about five different types of creativity. Please take your own notes on the outline provided.

For these students, no mention was made of the instructor notes until after the lecture.

Students were also be randomly assigned to a study technique condition (Rereading, Examples, Summarizing). Students in the Rereading condition saw the following instructions:

During the lecture, there will be short breaks, of two minutes each, after each major topic. Please take this time to reread your notes, to help you remember and understand them. You will have two minutes during each break.

Students in the Summarizing condition saw the following instructions:

During the lecture, there will be short breaks, of two minutes each, after each major topic. Please take this time to summarize, in a couple of sentences, the information in this section. You will have two minutes during each break.

Students in the Examples condition saw the following instructions:

During the lecture, there will be short breaks, of two minutes each, after each major topic. Please take this time to think of one 
example, from your own experience, of this type of creativity.

You will have two minutes during each break.

After receiving note taking and study technique instructions according to their group, subjects viewed the 20-minute lecture, with five two-minute breaks (one after each topic).

Following the lecture period, students in the After lecture note condition were given the instructor notes. Then, all students were given a 15-minute free-study period. Afterwards, they turned in all their notes and study materials to the researcher.

At the second session, students were given a 15-minute study period to review their notes and other written materials. Next, they took the 48-question multiple-choice test about the lecture information. Finally, participants responded to the post-experiment questionnaire. 


\section{Results}

Students responding that they had prior knowledge of the types of creativity described in the lecture (34 participants out of a total of 240) were excluded from the analyses, and from the totals indicated below.

A manipulation check was performed to see whether students in the Summarizing or Examples groups did in fact generate summaries or examples in their notes. Of the 69 students in the Examples group, 71.01\% $(n=49)$ did write examples in as least half of the spaces provided, while $28.99 \%(n=20)$ did not. Of the 65 students in the Summarizing group, $80.00 \%(n=52)$ did write summaries in as least half of the spaces provided, while $20.00 \%(n=13)$ did not. Unfortunately, it was not possible to conduct the same manipulation check for the 72 students in the Rereading group, as rereading leaves no observable artifact in the notes.

All analyses were performed twice, either including or excluding students who failed to pass the manipulation check. None of the analyses produced different findings, in terms of statistical significance, depending on this filter. Because the results were similar in either case, and because of concern that no students in the Rereading group could be excluded on the basis of the manipulation check, all the analyses reported below were conducted including the entire student sample (with the exception of those who indicated that they had prior knowledge).

\section{Word Count}

For the dependent variable of personal note length, the number of words written down by the subject (not including any summaries or examples) was counted and treated 
as a continuous variable. To test the Hypothesis 1 , that students receiving instructor notes prior to lecture would take fewer of their own notes than would students receiving instructor notes after lecture, a two-factor between-subjects analyses of variance (ANOVA) was conducted with timing of instructor notes (Before, After) and study technique (Rereading, Summarizing, Examples) as the independent variables and word count as the dependent variable.

Students who received instructor notes prior to viewing the lecture $(M=179.27$, $S D=115.74, n=105)$ wrote down an average of 82.33 fewer words than students who received instructor notes after viewing the lecture $(M=261.60, S D=98.10, n=101)$. The overall analysis for word count revealed a significant main effect for timing of instructor-provided notes, $F(1,200)=29.81, p<.001, R^{2}=.13$. This result supports Hypothesis 1, as students who received instructor notes prior to viewing the lecture did in fact take fewer of their own notes than students who received the same notes after viewing the lecture.

Examining word count by the independent variable of study technique, the Rereading group $(M=218.81, S D=103.67, n=72)$, the Summarizing group $(M=$ 225.38, $S D=110.29, n=65)$, and the Examples group $(M=215.09, S D=130.59, n=$ 169) all groups wrote a comparable number of words (words written by the participant as part of a Summary or Example were not included in "Word Count"). The overall analysis for word count found no main effect for study technique, $F(2,200)=.15, p=$ $.86, R^{2}=.00$, and no significant interaction between timing of instructor notes and study technique, $F(2,200)=1.68, p=.19, R^{2}=.01$. These results are summarized in Figure 1 . 


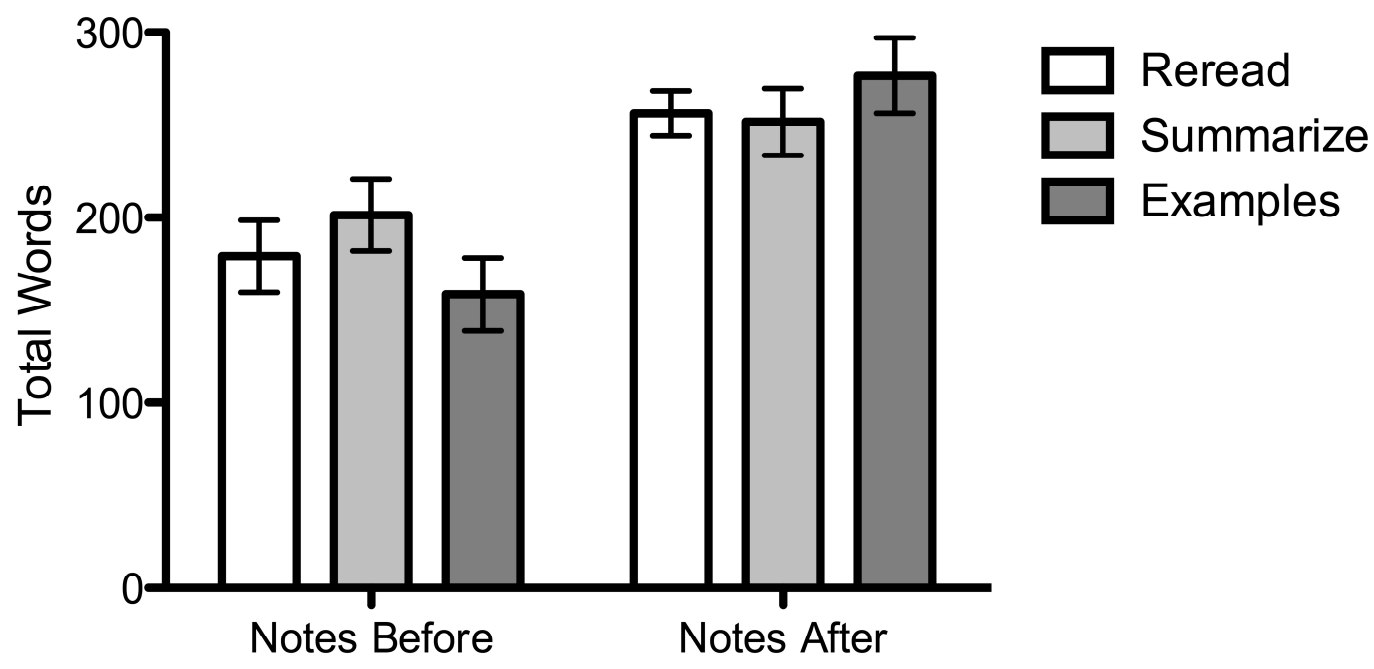

Figure 1. Mean words written in personal notes as a function of timing of instructorprovided notes and assigned study technique. Standard errors are represented in the figure by the error bars attached to each column. 
A more detailed examination of a small sample (approximately 1000 words across six participants, one per condition) of students' personal notes found that fewer than $10 \%$ of the words written down did not appear in the instructor lecture guide. This proportion was evident across all participants sampled. This indicates that for the most part, students were taking verbatim notes, as opposed to incorporating their own original ideas.

This closer examination of student notes also revealed that they were a relatively small subset of the total number of ideas presented in the lecture. If each concept in the instructor outline (indicated by a new line beginning with a capital letter that is not a proper name) is counted as one idea, for a total of 107 idea units, the small sample of student notes included an average of only 36 idea units recorded in students personal notes.

\section{Factual Recall}

The dependent variable of Factual Recall was measured by the Factual items on the multiple-choice test, expressed as a number of correct answers (out of 32 possible) for those items. Students in the Notes Before condition $(M=21.16, S D=4.79, n=105)$ performed comparably on the Factual Recall test to the students in the Notes After condition $(M=20.87, S D=4.43, n=101)$. When compared by study technique, the Rereading group $(M=20.53, S D=4.70, n=72)$, Summarizing group $(M=21.02, S D=$ 4.52, $n=65)$ and Examples group $(M=21.54, S D=4.61, n=69)$ also performed similarly on Factual Recall. The overall analysis for factual recall indicated no main effects for timing of instructor-provided notes, $F(1,200)=.20, p=.66, R^{2}=.00$, study technique, $F(2,200)=.83, p=.44, R^{2}=.01$, or timing of notes $\mathrm{x}$ study technique 
interaction, $F(2,200)=.39, p=.68, R^{2}=.00$. These results are consistent with Hypothesis $2 \mathrm{a}$, which predicted that all groups would perform similarly on measures of memorization. These results are summarized in Figure 2. 


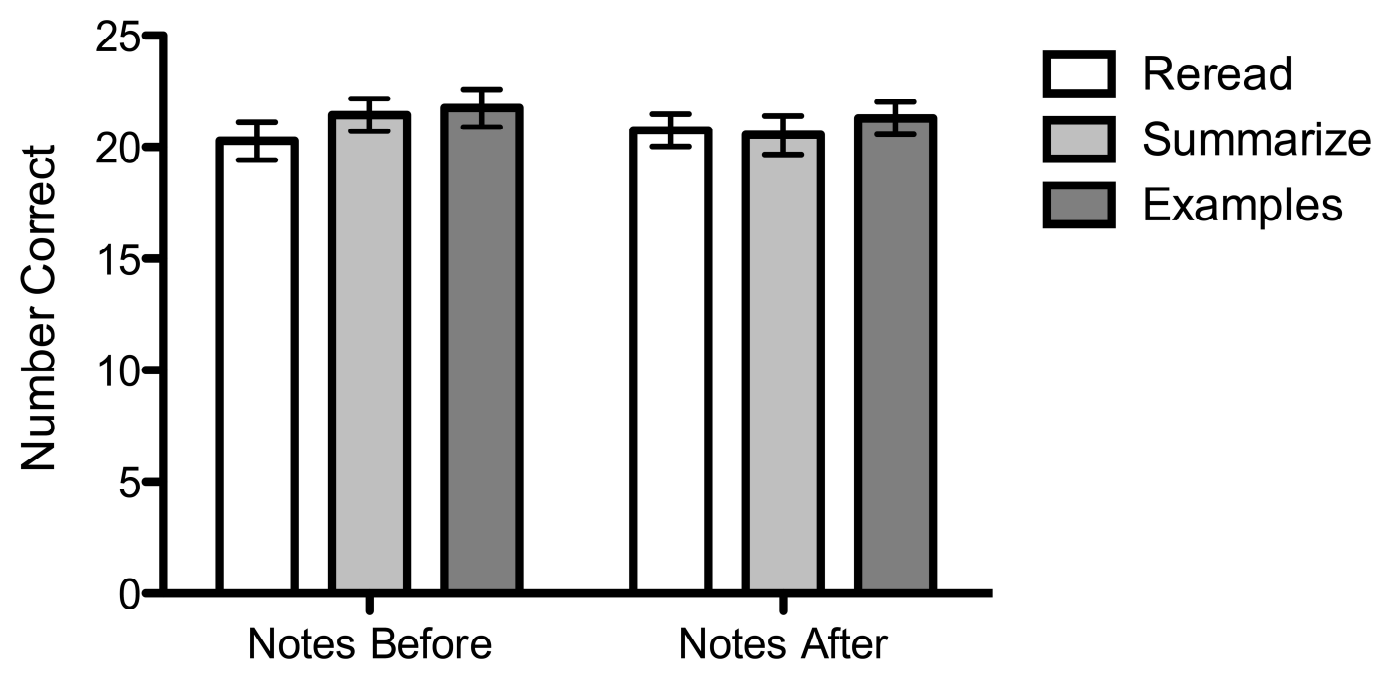

Figure 2. Mean number of correct answers on factual recall test items as a function of timing of instructor-provided notes and assigned study technique. Standard errors are represented in the figure by the error bars attached to each column. 


\section{Application}

The dependent variable of Application was measured by the Application items on the multiple-choice test, expressed as a number of correct answers (out of 16 possible) for those items. Students in the Notes Before condition $(M=9.21, S D=2.92, n=105)$ performed comparably on the Application test to the students in the Notes After condition $(M=8.77, S D=3.03, n=101)$. When compared by study technique, Rereading group $(M=8.50, S D=2.96, n=72)$, Summarizing group $(M=8.85, S D=2.98, n=65)$, and Examples group $(M=9.65, S D=2.92, n=69)$ also performed similarly on Application. The overall analysis for application indicated no main effects for timing of instructorprovided notes, $F(1,200)=1.05, p=.31, R^{2}=.01$, study technique, $F(2,200)=2.71, p=$ $.07, R^{2}=.03$, or timing of notes x study technique interaction, $F(2,200)=.19, p=.83, R^{2}$ $=.00$. These results fail to support Hypothesis $2 \mathrm{~b}$, that individuals receiving instructor notes after lecture would perform better on application measures than individuals receiving instructor notes prior to lecture.

Students instructed to provide examples for each type of learning scored an average of 9.65 correct answers $(n=69)$ on the application measure, while students instructed to summarize their notes scored an average of 8.85 correct answers $(n=65)$, and students instructed to reread their notes received an average of 8.50 correct answers $(n=72)$. Though it does not reach significance, this pattern of results is fully consistent with Hypothesis 3, in which students providing real-life examples of the lecture topics would perform better than those creating summaries of the information, and that these students would outperform those who only reread their notes for review. 
Because the main analysis for study technique was so close to significance at $\mathrm{alpha}=.05$, simple comparisons were performed between the Rereading, Summarizing, and Examples groups. These comparisons showed no significant difference in average correct Application answers between the Rereading and Summarizing groups, $F(1,157)$ $=.09, p=.77, R^{2}=.00$, or between the Examples and Summarizing groups, $F(1,155)=$ $3.54, p=.06, R^{2}=.02$. However, mean Application scores were significantly higher in the Examples group than the Rereading group, $F(1,156)=4.79, p=.03, R^{2}=.03$. These results are summarized in Figure 3. 


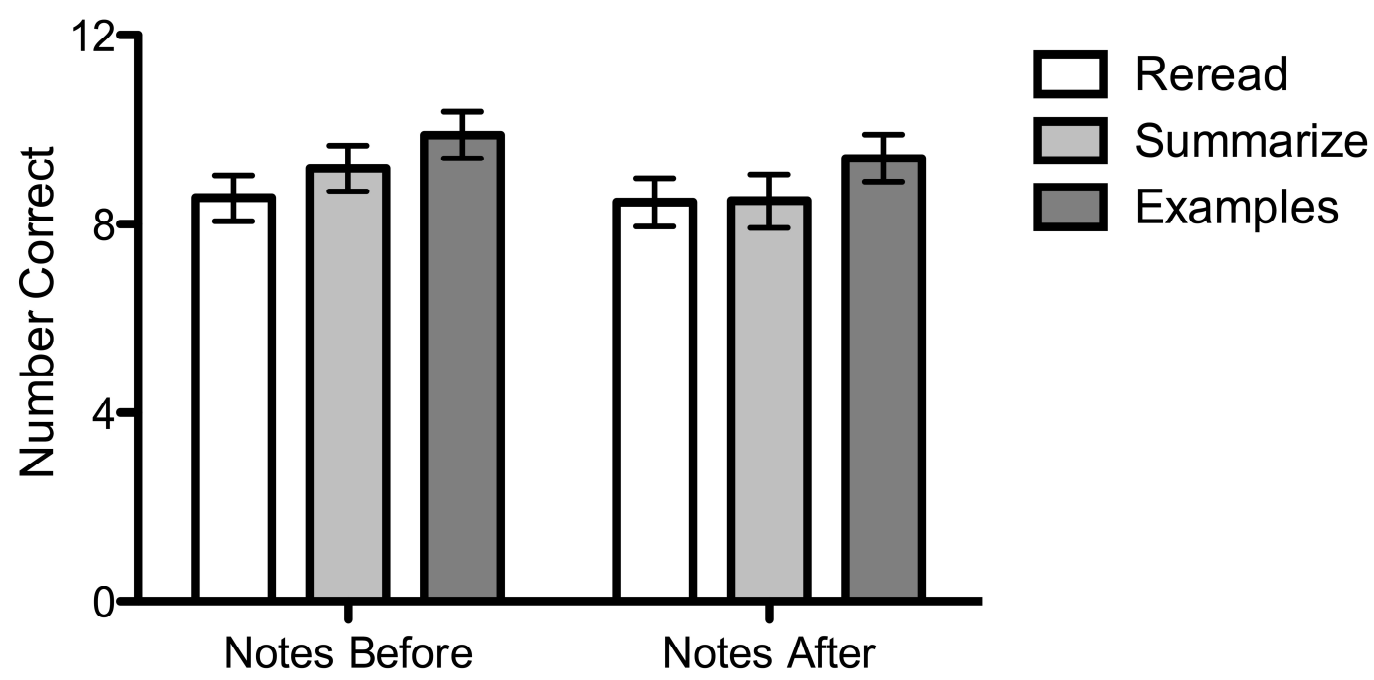

Figure 3. Mean number of correct answers on application test items as a function of timing of instructor-provided notes and assigned study technique. Standard errors are represented in the figure by the error bars attached to each column. 


\section{Discussion}

The most striking finding of this study is that students who were provided a complete lecture outline in advance took fewer notes but did no worse on tests of factual recall or application than did students who took more notes after receiving the complete lecture outline only after the fact. This finding fails to support the encoding value of note taking. Students who did not know they would be receiving a complete outline after the lecture wrote an average of 82.33 more words in their personal notes than did students who received this outline in advance. However, this additional effort did not translate into an improvement in performance on either memorization or transfer measures. It is unclear what this result means in terms of generative vs. cognitive load theory, because the between-group comparison indicated neither a beneficial nor detrimental effect of writing a larger volume of personal notes. Of course, an additional relevant question is to what degree personal note taking during lecture is, in fact, a generative process, an increase in cognitive load, or neither. The fact that the vast majority of personal notes taken by students in both conditions consisted largely of verbatim transcriptions of lecture concepts (see Results: Word Count) may mean that the way students typically take notes, at least in a situation like this experiment, is neither generative nor a heavy cognitive load.

In contrast to the effect on personal note taking behavior produced by the timing of instructor-provided notes, the effects produced by directing students to reread, summarize, or generate examples for their notes were much less impressive. The fact that students instructed to think of their own examples did slightly better on Application 
test questions than did students who simply reread their notes does appear to lend some support to generative theory. Being asked to think of personal examples would encourage students to develop external connections with the lecture content, which may have helped them to categorize the novel examples that were presented on the test. In any event, this result implies that generating novel examples during breaks in the lecture could reasonably be classified as germane cognitive load, in which the activity itself involves the students in concept acquisition.

Based on the results of this experiment, both generative theory and cognitive load theory may be important considerations in how to structure student note taking during lecture for maximum benefit. The limitations of cognitive load would logically be most relevant while the lecturer is speaking, such that students may benefit from not having to listen and write notes at the same time. On the other hand, encouraging students to generate connections with the content during breaks in the lecture presentation could improve test performance later without imposing an additional cognitive load during a time when students are already taxed by trying to listen to and comprehend the ideas being presented in the lecture.

The controversy over constructivism as a theory of learning vs. constructivism as a prescription for instruction is an important one in this context. Mayer (2009) warns against the constructivist teaching fallacy, in which both high cognitive activity and high behavioral activity are assumed to promote deeper learning. He points out that some "active" instructional methods (such as discovery learning) can lead to high behavioral activity but low cognitive activity on the part of the learner, while other "passive" 
methods (such as well-designed multimedia lessons) can lead to low behavioral activity but high cognitive activity. It may be that student note taking during lecture, while increasing student behavioral activity, does not increase student cognitive activity. Bretzing and Kulhavy (1981) found that students typically attempted to copy ideas verbatim, and an examination of the notes produced in the current study shows the same pattern. This would indeed suggest a relatively low level of student cognitive processing even if, behaviorally, the students stay very active trying to keep up writing their notes at the pace of the lecture presentation (assuming that students' failure to record the majority of important lecture ideas was the result of insufficient time, rather than a lack of interest or motivation, or due to some other reason).

Like much previous research in this area, the results of this experiment strongly support the storage function of notes, at least from the perspective of the students participating. In the post-experiment survey, 184 participants, or $76.67 \%$, indicated that they relied most on "the notes given to me" during the study period. Only 15 participants (6.25\%) selected only "the notes I took," although an additional 11 participants indicated that they relied on both. In other words, regardless of how they may have perceived any learning benefit to writing their own notes during the lecture, when it came to the study period, most of the students did not rely on the notes they took themselves, favoring the complete lecture outline instead. This behavior does suggest that at least in the context of this experiment, any internal or external connections that students may have made during the note taking period would have only a diminished impact on their learning if they did not focus their later studying on what they wrote down during the lecture. Kobayashi's 
2005 and 2006 meta-analyses found a large (.74-.76) effect size estimate of the value of note taking plus review, compared to only .22 for note taking without review. We can also compare the current study to one conducted by Kiewra et al. (1991) in which, on the synthesis test, students in the storage-only (borrowed notes) condition significantly outperformed students in the encoding-only (took notes, no review) group. One might infer from this finding that, in the current study, most students' personal note taking during the lecture was of minimal learning benefit, given that they did not review those notes later during the study period.

\section{Limitations}

Although providing instructor notes before or after the lecture had a large effect on students' note taking behavior even as it had no effect on test performance, we need to be cautious in interpreting the meaning for the encoding function of note taking. One possibility is that the content of the lecture may influence the encoding effect. If there are many facts and details to memorize, simply copying down these details may not be particularly helpful, particularly if it disrupts listening and understanding during the lecture.

An additional problem is that although viewing the lecture was intended to be the "encoding period" for students in this experiment, it is reasonable to say that both the immediate study period, and the follow-up study period a week later, could also have been used by students to encode the material. Thus, it is possible that any encoding effect caused by manipulating student note taking behavior during the lecture itself may have been overwhelmed by the encoding effect of later study periods. Different experiments 
including groups of students who "missed" lecture and got to study only the notes, or groups who watched the lecture but had no study period might do better at isolating the encoding effect of note taking specifically during the lecture period.

Next, it must be acknowledged that the manipulation of directing students to reread, summarize, or generate examples for their notes had a very weak effect in the current study. Kobayashi's (2005) meta-analysis uncovered a consistent pattern that in general, positive interventions did not enhance the benefits of note taking, and that more extensive training and practice, including feedback, is necessary to improve students' personal note taking. His (2006) meta-analysis found that overall, researchers attempting to apply interventions to students' spontaneous note taking/reviewing produced a modest effect (mean weighted effect size of .36), which of course is still substantially larger than the .00-.03 effect sizes achieved in the current study. Effective training in generative note taking may require more guidance and practice than is typically provided in a brief research study, and the instructional procedure in the current study may have exacerbated this general problem. In the current experiment, students were given only a single written instruction, with no further explanation from the experimenter about what they were supposed to do. Even if students asked questions about the procedure, the experimenter could only instruct them to follow the written instructions to the best of their ability, without offering any additional clarification. Only approximately three-quarters of the students followed the instructions at all, and those who did still had no training in how to generate better-quality summaries or examples. It is possible that additional time devoted 
to practice, feedback, and focused study may enhance the benefits of instructing students to perform extra-note taking activities targeting at enhancing generative processing.

In addition, the modifications students were instructed to make during this experiment may not have been ideal. For example, one could argue that drawing comparisons and contrasts among the five different types of creativity, as opposed to summarizing one type at a type, would have been a more beneficial activity for the students in the Summarizing condition.

Of course, in this experiment, the study technique assigned explained very little of the variance in test performance among the students in this sample. It must be acknowledged that in a diverse student population, the primary determinant of whether a student does well or poorly on a test during an isolated experiment is the personal characteristics of that student, particularly when no grade is at stake and no other incentives for good performance are provided. For example, in this study, student grade point average correlated $r=.17\left(p=.01, R^{2}=.03\right)$ on the factual recall test and $r=.14(p$ $=.03, R^{2}=.02$ ) on the application test. Student motivation self-ratings averaged only 2.85 , which is below the midpoint on the 1 to 5 scale provided on the post-experiment survey, and correlated $r=.13\left(p=.05, R^{2}=.02\right)$ on the factual recall test and $r=.19(p=$ $.004, R^{2}=.03$ ) on the application test. It would be unrealistic to expect a single note taking intervention to change consistent patterns of student performance. However, in spite of the relatively small impact of note taking intervention on test scores in this study, because the instructor in a large classroom is generally obligated to provide all students a 
consistent learning experience, any intervention that might improve average performance, even by a small margin, should be considered valuable.

\section{Future Research}

Perhaps the greatest open question resulting from this study is whether having students generate novel examples, facilitating the creation of external connections to lecture material, could be made more beneficial. Given that past research in this area has been largely unsuccessful in enhancing the benefits of note taking through positive interventions (Kobayashi, 2005), it appears that if such a benefit is to be achieved, more extensive training and practice, and/or a more realistic classroom environment might be necessary. It would be interesting to train students in a real classroom in how to use these techniques to learn content relevant to their personal interest and course grades. The extended time period to learn these techniques, along with a real-world incentive for doing so, may make a substantial difference.

Because the current study found that leading students to write down a larger quantity of notes out of perceived necessity did not improve test performance, it appears that, at least in the context of this laboratory experiment, instructors' concerns that providing students with complete lecture notes in advance might reduce their generative processing during the lecture are unfounded. Of course, in a real-life classroom situation, other issues intervene. For example, an instructor might find that providing complete lecture notes reduces class attendance (though one might also point out the 1988 study by Kiewra and his colleagues that found that students who borrowed notes without attending lecture performed comparably to students who attended the lecture, took, and studied 
their own notes). Further research may illuminate the real-world effects of providing complete lecture notes to students in an actual college class.

Additional topics for future research include an examination of how the content of students' personal notes may change when they are presented a complete outline in advance. It has been established in this study and others (i.e. Morgan et al, 1988) that students write fewer of their own notes when they are provided a set of instructor notes. In this study, these notes appeared to merely a subset of the complete instructor outline (see Results: Word Count). However, it is impossible to tell what particular learning goal any given participant had in writing down those particular concepts, rather than others. It is possible that students working from a complete instructor outline while listening to the lecture were able to be more selective and intentional in what notes they wrote down, in ways that are not obvious to an experimenter examining these notes after the fact. It would be interesting to somehow examine the thoughts behind what goes into those students' notes: are they only a less-complete version of the notes students normally take, or are they actually selected to contribute to building internal or external connections? Does the style of notes taken under these conditions depend on student characteristics, such as grade point average, or year in school? Are there specific note taking intervention activities that are particularly effective when students are relieved of the burden of trying to write down everything? If so, what is the most effective way to teach these techniques?

In conclusion, the tension between cognitive load theory and generative theory in the context of student note taking during lecture was far from resolved by this study. 
Many interesting paths for investigation remain for us to understand how to best use the central concepts from each of these theories to enhance student learning in the classroom. 


\section{References}

Baker, L., \& Lombardi, B. R. (1985). Students' lecture notes and their relation to test performance. Teaching of Psychology, 12, 28-32.

Bretzing, B. H., \& Kulhavy, R. W. (1979). Note taking and depth of processing. Contemporary Educational Psychology, 4(2), 145-153.

Bretzing, B. H., \& Kulhavy, R. W. (1981). Note taking and passage style. Journal of Educational Psychology, 73(2), 242-250.

Carrier, C. A., \& Newell, K. J. (1984). What dental hygiene students think about note taking in lectures. Canadian Dental Hygienist, 18, 13-17.

Carrier, C. A., \& Titus, A. (1981). Effects of note taking pretraining and test mode expectations on learning from lectures. American Educational Research Journal, 18(4), 385-397.

Carrier, C. A., Williams, M. D., \& Dalgaard, B. R. (1988). College students' perceptions of notetaking and their relationship to selected learner characteristics and course achievement. Research in Higher Education, 28(3), 223-239.

Cohen, J. (1988). Statistical power analysis for the behavioral sciences (2nd ed.). Hillsdale, NJ: Erlbaum.

Craik, F. I. M., \& Lockhart, R. S. (1972). Levels of processing: A framework for memory research. Journal of Verbal Learning and Verbal Behavior, 11, 671-684.

Di Vesta, F. J., \& Gray, S. G. (1972). Listening and note taking. Journal of Educational Psychology, 64(3), 278-287.

Doctorow, M., Wittrock, M. C., \& Marks, C. (1978). Generative processes in reading comprehension. Journal of Educational Psychology, 70(2), 109-118.

Ellner, C. L. (1983). Piercing the college veil. In C. L. Ellner \& C. P. Barnes (Eds.), Studies of college teaching (pp. 183-193). Lexington, MA: D.C. Heath.

Fischer, C. G., \& Grant, G. E. (1983). Intellectual levels in college classrooms. In C. L. Ellner \& C. P. Barnes (Eds.), Studies of college teaching (pp. 47-60). Lexington, MA: D.C. Heath.

Frase, L. T. (1970). Boundary conditions for mathemagenic behaviors. Review of Educational Research, 40, 337-347. 
Hartley, J. (1983). Note taking research: Resetting the scoreboard. Bulletin of the British Psychological Society, 36, 13-14.

Hartley, J., \& Davies, I. K. (1978). Note-taking: A critical review. Programmed Learning and Educational Technology, 15(3), 207-224.

Kalyuga, S. (2007). Expertise reversal effect and its implications for learner-tailored instruction. Educational Psychology Review, 19(4), 509-539.

Kiewra, K. A. (1985). Providing the instructor's notes: An effective addition to student note taking. Educational Psychologist, 20(1), 33-39.

Kiewra, K. A. (1991). Aids to Lecture Learning. Educational Psychologist, 26(1), 37-53.

Kiewra, K. A., Dubois, N. F., Christensen, M., Kim, S., \& Lindberg, N. (1989). A more equitable account of the note-taking functions in learning from lecture and from text. Journal of Instructional Science, 18, 217-232.

Kiewra, K. A., DuBois, N. F., Christian, D., \& McShane, A. (1988). Providing study notes: Comparison of three types of notes for review. Journal of Educational Psychology, 80(4), 595-597.

Kiewra, K. A., DuBois, N. F., Christian, D., McShane, A., Meyerhoffer, M., \& Roskelley, D. (1991). Note-taking functions and techniques. Journal of Educational Psychology, 83(2), 240-245.

Kiewra, K. A., \& Fletcher, H. J. (1984). The relationship between note taking variables and achievement measures. Human Learning, 3, 273-280.

King, A. (1992). Comparison of self-questioning, summarizing, and note taking-review as strategies for learning from lectures. American Educational Research Journal, 29(2), 303-323.

Kintsch, W. (2009). Learning and constructivism. In S. Tobias \& T. M. Duffy (Eds.), Constructivist theory applied to education: Success or failure? (pp. 223-241). New York: Routledge.

Kirschner, P. A., Sweller, J., \& Clark, R. (2006). Why minimal guidance during instruction does not work: An analysis of the failure of constructivist, discovery, problem-based, experiential, and inquiry-based teaching. Educational Psychologist, 41(2), 75-86.

Kobayashi, K. (2005). What limits the encoding effect of note-taking? A meta-analytic examination. Contemporary Educational Psychology, 30(2), 242-262. 
Kobayashi, K. (2006). Combined effects of note-taking/-reviewing on learning and the enhancement through interventions: A meta-analytic review. Educational Psychology, 26(3), 459-477.

Lee, Y., \& Nelson, D. W. (2005). Viewing or visualizing: Which concept map strategy works best on problem-solving performance? British Journal of Educational Technology, 36(2), 193-203.

Mayer, R. E. (1984). Aids to text comprehension. Educational Psychologist, 19(1), 3042.

Mayer, R. E. (2004). Should there be a three-strikes rule against pure discovery learning? The case for guided methods of instruction. American Psychologist, 59(1), 14-19.

Mayer, R. E. (2009). Constructivism as a theory of learning versus constructivism as a prescription for instruction. In S. Tobias, \& T. M. Duffy (Eds.), Constructivist theory applied to education: Success or failure? (pp. 184-200). New York: Routledge.

Morgan, C. H., Lilley, J. D., \& Boreham, N. C. (1988). Learning from lectures: the effect of varying the detail in lecture handouts on note-taking and recall. Applied Cognitive Psychology, 2(2), 115-122.

Paas, F., Renkl, A., \& Sweller, J. (2003). Cognitive load theory and instructional design: recent developments. Educational Psychologist, 38(1), 1-4.

Peper, R. J., \& Mayer, R. E. (1986). Generative effects of note-taking during science lectures. Journal of Educational Psychology, 78(1), 34-38.

Peters, D. L. (1972). Effects of note-taking and rate of presentation on short-term objective test performance. Journal of Educational Psychology, 63(3), 276-280.

Renkl, A., \& Atkinson, R. K. (2003). Structuring the transition from example study to problem solving in cognitive skill acquisition: A cognitive load perspective. Educational Psychologist, 38(1), 15-22.

Ryan, M. T. (1982). Effects of paraphrase notetaking on prose learning (Doctoral dissertation, University of Connecticut). Retrieved from Dissertation Abstracts International. (UMI No. 820356).

Smith, D. G. (1983). Instruction and outcomes in an undergraduate setting. In C. L. Ellner \& C. P. Barnes (Eds.), Studies of college teaching (pp. 83-116). Lexington, MA: D.C. Heath. 
Stefanou, C., Hoffman, L., \& Vielee, N. (2008). Note-taking in the college classroom as evidence of generative learning. Learning Environments Research, 11(1), 1-17.

Stull, A. T., \& Mayer, R. E. (2007). Learning by doing versus learning by viewing: Three experimental comparisons of learner-generated versus author-provided graphic organizers. Journal of Educational Psychology, 99(4), 808-820.

Tobias, S. (1989). Another look at research on the adaptation of instruction to student characteristics. Educational Psychologist, 24(3), 213-227.

Van Merriënboer, J. J. G., Kirschner, P. A., \& Kester, L. (2003). Taking the load off a learner's mind: Instructional design for complex learning. Educational Psychologist, 38(1), 5-13.

Van Meter, P., Yokoi, L., \& Pressley, M. (1994) College students' theory of note-taking derived from their perceptions of note-taking. Journal of Educational Psychology, 86(3), 323-338.

Wirt, J., Choy, S., Greald, D., Provasnik, S., Rooney, P., \& Watanabe, S. (2001). The condition of education 2002 (NCES Publication No. 2001072). Washington, DC: National Center for Education Statistics, U.S. Department of Education.

Wittrock, M. C. (1974). Learning as a generative process. Educational Psychologist, 11(2), 87-95.

Wittrock, M. C. (1990). Generative Processes of Comprehension. Educational Psychologist, 24(4), 345-376.

Wittrock, M. C. (1992). Generative learning processes of the brain. Educational Psychologist, 27(4), 531-541.

Wittrock, M. C., \& Carter, J. F. (1975). Generative processing of organized information. Unpublished manuscript. 


\section{Appendix A}

\section{Lecture Transcript}

Creativity

The primary purpose of this lecture is to discuss four types of real-life creativity and to explain how real-life creativity differs from the type of creativity stressed in creativity training programs in the school.

A careful analysis of real-life creativity suggests that there are four distinct types: expressive, adaptive, innovative, and emergentative. As you will soon learn, these types of creativity differ with respect to their definition, the time demand necessary to display and to develop creativity, the motivation for creativity, the distinguishing characteristic(s) and the related characteristics or dimensions. In discussing each type of creativity examples will be presented, and common myths will be described and expelled.

Expressive creativity is the ability to generate a rapid or extremely rapid response in a situation. Oftentimes, the person has to respond within the range of a few seconds or less. The distinguishing characteristic of a skilled expressively creative person is the ability of the person to maintain the flow of responses in a rapidly occurring sequence. Therefore, consistency and automaticity are dimensions of this critical characteristic of expressive creativity. Examples include an athlete feigning an opponent in a sporting event, a musician playing progressive jazz, an actor improvising in the theatre, a comedian interacting with an audience, or a college professor answering questions rapidly and succinctly. The motive for the expressively creative person, then, is to create a momentary flash of brilliance that fits the immediate situation yet stands apart from 
typical responses. Essentially, the expressively creative person has mastered a calculated style. In a sense, the creativity stems from the development of the style. This is another important dimension. But there are still other important dimensions. Another dimension of critical significance is the ability of the person to rapidly perceive patterns, and/or to even anticipate future patterns. Rapid and accurate interpretation of the environment is a necessary condition for skilled expressive creativity. This sensitivity usually takes 8-12 years to develop. A final critical skill associated with expressive creativity is timing. The person has to learn when to make the responses.

The myth associated with this type of creativity is the belief that the creative response is spontaneous and that the person making the response is spontaneous. Upon more careful analysis, however, we discover that the person making the response has overpracticed the response. In a sense, the expressively creative person makes us believe the response is spontaneous, much in the same manner that a magician deceives us. In actuality, the person has mastered an habitual calculated style. The responses we observe are manifestations of that highly practiced style.

A second type of real-life creativity is adaptive creativity. Adaptive creativity is the ability to use past knowledge and strategies to accommodate to problem solving situations. While the time demands of adaptive creativity are considerably longer than expressive creativity, most forms of adaptive creativity occur within the span of a day to several weeks. As you will see this contrasts with innovative and emergentative creativity. The distinguishing characteristics of a skilled adaptively creative person are the ability to analyze day-to-day problems, plan effective solutions, and then execute the 
plans successfully. For the adaptively creative person, the motive is to maintain the status quo or to slightly improve the status quo. Examples include any of the day-to-day problems that a homemaker or a skilled person in a profession or a vocation would have to solve. For example, a homemaker may have to use adaptive creativity to plan and execute a new house-cleaning and meal preparation strategy when it is learned that unexpected guests will soon be arriving. A college professor may have to draw on similar past experiences when planning and organizing a conference presentation for the first time. Essentially, the adaptively creative person has mastered effective day-to-day problem solving strategies. In a sense, the creativity stems from the flexibility brought about by extensive practical experience. Flexibility is not, however, the only important dimension. As with expressive creativity, pattern recognition is a crucial skill. The differences between pattern recognition in expressive creativity and adaptive creativity are significant. For expressive creativity, pattern recognition is instantaneous. For adaptive creativity pattern recognition is oftentimes much slower.

In fact, quite often the adaptively creative person develops effective and systematic search strategies to compare current situations with previous situations. The creativity occurs when the person identifies the similarities between the two situations, and then combines strategies in novel ways to solve the problem.

The myth associated with this type of creativity is the belief that flexibility is the key to problem solving. In one sense, it is. In another sense, though, we note that adaptively creative people are highly systematic when they solve problems. They are systematically flexible. The emphasis is on the word "systematic." Upon careful analysis 
we discover that adaptively creative people have overlearned effective problem solving strategies. They know how to identify similarities between diverse situations, and then use those strategies in new ways and in new situations. Adaptive creativity, for these reasons, can only be mastered over a period of many years.

Innovative creativity differs significantly from expressive and adaptive creativity. Innovative creativity refers to the person's ability to significantly change or alter a major process, product, or school of thought. The distinct characteristic of innovative creativity is the person's desire to make significant changes. Examples of innovative creative people include inventors who significantly improve products or produce new products; writers, artists, and musicians who alter artistic styles; scientists who alter theories; or coaches who create a modification of the typical defensive strategies to be used in a match. The innovator is concerned with significant improvement. Quite often the motivation of the innovator stems from dissatisfaction, which results in a desire to make a significant change. One of the central characteristics of innovative people, therefore, is their use of personal models, beliefs, ideas, analogies, or styles to guide their productivity. In a sense, their creativity is highly predictable. Many innovators are highly driven people. They dwell on their ideas for lengthy periods of time. There is no spontaneous response. In some cases, they are consumed for their total adult lives.

The myth associated with this type of creativity is the belief that innovative creativity stems from originality. The originality, however, stems from the highly developed model or idea, not from a fluent or flexible cognitive style. Originality, obviously, is important. What is much more important, however, is how the innovator 
consistently re-uses a major model, idea, image, metaphor, or similar strategy over and over again to guide the thought processes. Innovative people are driven -- they are goaldirected. They are interested in change. Paradoxically, while they maintain cognitive flexibility, they carefully control their thought processes. For example, most of Thomas Edison's inventions stem from his understanding of several basic principles discovered early in his productive years. He was a master of analogical thinking. Monet's impressionistic painting style is another striking example. We look at his work and are amazed at Monet's apparent spontaneity. What most people don't know is that Monet used a highly systematic strategy to produce his paintings.

A fine line exists between innovative creativity and emergentative creativity. Emergentative creativity refers to the person's ability to profoundly change existing ideas, beliefs, or styles. The change is so profound that the whole direction of a discipline is reshaped. Obviously, such a significant change involves a lifetime of experience and thinking in a particular field. The distinguishing characteristic of the emergentative creative person is his/her proclivity to attack basic assumptions. The emergentative creative person has more faith in his/her ideas than in the underlying assumptions of a discipline. Examples of emergentative creative people are people who have given rise to intellectual or stylistic revolutions: Copernicus, Darwin, Freud, Einstein, Marx, Beethoven, and Picasso are such examples.

Emergentative creativity includes other dimensions. Emergentatively creative people are great risk takers. This may stem from their intense motivation to set trends. But, emergentatively creative people are not only trend setters but trend followers as 
well. When an idea is ready to be developed or discovered, the emergentative person is there with his/her tremendous knowledge of the past and present, willing and able to redirect the future.

Significant changes are made through Janusian thinking, a characteristic of emergentatively creative people. Janusian thinking underlies the ability to reconcile apparent opposites and thereby construct new connections. For example, Pasteur reconciled the paradox of safe-attack in discovering pasturization. He searched for a means to attack milk's bacteria safely so that the milk could not be destroyed.

Emergentatively creative people also display a metaphorical reasoning dimension in guiding the development of their ideas. Thus they have mastered Aristotle's famous quote: "The greatest thing by far is to be master of the metaphor." As Jacob Bronowski said, "A person becomes creative... when one finds a new unity in the variety of nature... a likeness between things which were not thought alike before, and this gives one a sense both of richness and of understanding."

The myth associated with this type of creativity is the belief that the products or ideas of these great minds rise above the times, i.e., the person's genius and originality contributes much more to the production of the idea or product than the Zeitgeist. The Zeitgeist consists of the collective set of beliefs, ideas, assumptions, and products in existence at the time the person produces the emergentative idea. Upon more careful analysis, however, a paradox is uncovered.

The emergentative creative person is a tremendous synthesizer -- capable of sensing incongruities in theories as well as sensing the direction of the Zeitgeist. This 
proclivity gives rise to a stystematic account of the past and present aimed at the redirection of the future. Although the creative person has taken what appears to be a giant leap on a moonless night, in actuality, he/she has taken, through a synthesis of available knowledge, the next calculated step in a sunlit day. Their apparent originality is a manifestation of their unique ability to read the past and the present.

In contrast to these four types of real-life creativity, brief mention should be made of the type of creativity often assessed and promoted in school settings. School-oriented creativity usually involves the generation of a reasonably novel, but unskilled rapid response. The distinguishing features of school-oriented creativity are fluency (the ability to produce rapid responses), flexibility (the ability to change the direction of one's thoughts), and originality (the ability to produce relatively novel responses). Same examples include doodling, finger painting, occasional humor, thinking of a variety of uses for a brick and similar activities.

The myth is that these sorts of creative behaviors are related to real-life creativity. That is simply not the case. School-oriented creativity does not require skills, it does not require systematic strategies, and it does not require well-developed style as do the forms of real-life creativity.

Furthermore there is no real motivation to perform creatively on these schooloriented tasks other than personal satisfaction. No meaningful thought or product is derived and practically no skill is required. Furthermore, it should be apparent that the time commitment for this type of creativity is always minimal. 


\section{Appendix B}

\section{Lecture Outlines}

\section{Creativity}

Types

Definition

Time Demand

Display $\quad$ Few seconds or less

Development 8-12 years

Motivation

apart

Distinguishing

Characteristics

Related

Characteristics

Examples

Myths

Myths Dispelled

Expressive

Consistency

Automaticity

Calculated style

Actor improvising
Ability to generate rapid response

Create momentary flash of brilliance that is appropriate, yet stands

Maintain flow of responses in rapidly occurring sequence

Rapidly perceive patterns

Anticipate future patterns

Rapid and accurate interpretation of environment

Timing--when to make the response

Athlete feigning opponent

Musician playing progressive jazz

Comedian interacting

Professor answering questions rapidly and succinctly

Creative response is spontaneous and person is spontaneous

Person has actually overpracticed the response

Person makes us believe response is spontaneous like a magician deceives us

Person has actually developed habitual and calculated style that produces the response 


\section{Creativity}

Types

Definition

Time Demand
Display
Day to several weeks

Developed

Motivation

Distinguishing

Characteristics

Related

Characteristics

Examples

Myths

Myths Dispelled

Adaptive

Many years

Flexibility

Pattern recognition previous situations solve the problem
Ability to use past knowledge and strategies to accommodate to problem solving situations

To maintain or slightly improve the status quo

Ability to analyze day-to-day problems

Plan effective solutions

Execute successful plans

Slower than for expressive creativity

Develops systematic search strategies to compare current and

Identifies similarities and combines strategies in novel ways to

Homemaker who plans and executes a cleaning and meal planning strategy when unexpected guests are arriving A college professor who draws on past experiences to plan and organize a first presentation

Flexibility is the key to problem solving

Person actually highly systematic

Has overlearned effective strategies

Can identify similarities between situations

Can use strategies in new ways and new situations 


\section{Creativity}

Types Innovative

Definition

Ability to significantly change a major process, product, or school of thought

Time Demand

Display No spontaneous response

Development Lengthy periods of time

Total adult life

Motivation

Stems from dissatisfaction

Distinguishing

Characteristics

Desire to make significant changes

Related

Use of personal models, beliefs, analogies or styles

Characteristics

Highly predictable creativity

Highly driven people

Goal directed

Interested in change

Carefully control thought processes while maintaining cognitive flexibility

Examples Inventors who improve or produce products

Writers, artists

Musicians who alter styles

Scientists who alter theories

Coaches who modify defensive strategy

Edison's inventions stem from basic principles discovered early in productive years

Monet's painting style based on systematic strategy

Myths

Stems from originality

Myths Dispelled Originality stems from highly developed model or idea, not from fluent or flexible cognitive style

Innovator re-uses major model, idea, image, metaphor or similar strategy over and over to guide thought processes 


\section{Creativity}

Types Emergentative

Definition Ability to profoundly change existing ideas, beliefs or styles Whole direction of discipline is reshaped

Time Demand

Display $\square \quad$ Several years

Development Lifetime

Motivation To set trends

Distinguishing Proclivity to attack basic assumptions

$\checkmark$ Characteristics More faith in own ideas than in the assumptions of the discipline

Related Great risk takers

Characteristics Trend setters

Trend followers

Tremendous knowledge

There at the right time to redirect future Janusian thinking

Reconcile opposites to construct new connections

Metaphorical reasoning

Examples People who have given rise to intellectual or stylistic revolutions (e.g., Copernicus, Darwin, Freud, Einstein, Marx, Beethoven, Picasso)

Pasteur - reconciled paradox of safe-attack by attacking milk's bacteria safely

Aristotle - "Master of the metaphor"

Bronowski - "Find likeness in things not thought alike before"

Myths Products or ideas rise above the time or the Zeitgeist

Zeitgeist is existing beliefs, ideas, assumptions and products at the time

Myths Dispelled Tremendous synthesizer

Senses incongruities of theories

Senses direction of Zeitgeist

Reads past and present and takes next calculated step into the future 


\section{Creativity}

\section{Types}

Definition

Time Demand

Doodling

Finger painting

Occasional humor

Thinking of uses for a brick

Myths $\quad$ Related to real-life creativity

Myths Dispelled Does not require skills, strategies or style like real-life creativity No real motivation except personal satisfaction

No meaningful thought or product is derived 


\section{Appendix C}

\section{Blank Lecture Outlines}

\section{Creativity}

I. Expressive Creativity
A. Definition
B. Time Demands

C. Motivation

D. Distinguishing Characteristics

E. Related Characteristics

F. Examples

G. Myths/Myths Dispelled

II. Summary 


\section{Creativity}

I. Adaptive Creativity
A. Definition
B. Time Demands
C. Motivation
D. Distinguishing Characteristics

E. Related Characteristics

F. Examples

G. Myths/Myths Dispelled

II. Summary 


\section{Creativity}

\section{Innovative Creativity}
A. Definition
B. Time Demands
C. Motivation
D. Distinguishing Characteristics

E. Related Characteristics

F. Examples

G. Myths/Myths Dispelled

II. Summary 


\section{Creativity}

\section{Emergentative Creativity}
A. Definition
B. Time Demands
C. Motivation
D. Distinguishing Characteristics

E. Related Characteristics

F. Examples

G. Myths/Myths Dispelled

II. Summary 


\section{Creativity}

\section{School-Oriented Creativity}
A. Definition
B. Time Demands
C. Motivation
D. Distinguishing Characteristics

E. Related Characteristics

F. Examples

G. Myths/Myths Dispelled

II. Summary 


\section{Appendix D}

Content Tests

\section{ID \#}

Factual Recognition Test

\section{Part I}

For each of the following items there are two correct answers. List the two correct answers $(\mathrm{A}, \mathrm{B}, \mathrm{C}, \mathrm{D}, \mathrm{E})$ for each item in the spaces provided.
A. Emergentative Creativity
B. Innovative Creativity
C. Adaptive Creativity
D. School-Related Creativity
E. Expressive Creativity

_ 1,2 Which two types of creativity involve rapid responding?

3, 4 Which two types of creativity take a lifetime to develop?

5, 6 Which two types of creativity involve seeing similarities between "different" situations?

7, 8 Which two types of creativity involve making significant changes beyond the individual?

9, 10 Which two types of real-life creativity involve the possible production of several creative products within a single day?

11,12 Which two types of creativity require a thorough knowledge of the historical past?

13,14 Which two types of creativity are based on using the ideas of others? 


\section{Part II:}

For each of the sentences below, indicate with the appropriate letter, the type of creativity that is most closely associated with the provided statement.
A. Emergentative Creativity
B. Innovative Creativity
C. Adaptive Creativity
D. School-Related Creativity
E. Expressive Creativity

1. Ability to use past experience to solve everyday problems.

2. Actor improvising in the theater.

3. Inventors

4. Person creates a new product that improves an area.

5. Takes 8-12 years to develop creativity.

6. Involves fluency.

7. Takes several years to produce creative response.

8. Person can change direction of thoughts.

9. Attack basic assumptions.

10. Timing is a characteristic.

11. Time commitment is small.

12. Time to produce response is a day to several weeks.

13. Teacher preparing a presentation for fellow teachers.

14. Creative response is made in a few seconds.

15. Darwin

16. Person is dissatisfied with what exists. 
17. Person reshapes existing discipline.

18. Great risk takers. 


\section{Application Test}

For each of the following situations, indicate with the appropriate letter, the type of creativity that is most closely being described.
A. Emergentative Creativity
B. Innovative Creativity
C. Adaptive Creativity
D. School-Related Creativity
E. Expressive Creativity

1. After studying how mollusks adapt to their physical surroundings, researcher Benson applied his findings to the study of human psychological adaptation, and thereby spawned a new theory of human development.

2. When asked a question seemingly "out of the blue" about how his economic ideas were tied to the clamming industry, Senator Smith gave what appeared to be a fast and clever reply.

3. After watching student note taking over a long period of time, Professor Notebook came up with a new note taking style that improved the way students took notes.

4. During a coffee break at work one morning Marcy remarked to a colleague, "My life is a lot like this doughnut, it's not built around anything, and it's already a little stale".

5. Unable to handle the defensive pressure of many teams in his conference, Michigan Coach Fisher developed a new offensive formation which involved having two of his defensive players actually playing offense. When opponents had the basketball, Coach Fisher positioned one of his players at mid-court and another under his own basket. Whether the opponent scored or not, it was going to be a sure basket each time for Michigan.

6. At a party one evening guests were given a milk carton, 12 inches of string, and a spool of thread and told to make something. John made a train by cutting the spool to make wheels, making boxcars from the carton, and by using the string to join and to pull the cars.

7. Dr. J, the great NBA basketball player, once said, "I have no idea what I am going to do when I take off for the basket. I don't know whether I'm going righthand, left-hand, under-hand, or over-hand. I don't know whether I'm doublepumping or passing off. I simply react to the defense and do what feels right." 
8. He argued the assumption that the earth was at the center of the universe. Once that assumption was dispelled, the mathematical models that he originated readily fit the new notion that the sun was at the center of the Universe.

9. Josh was a natural camper his first time out. Although he forgot his canteen and knife, he used his shoe to drink from and scaled a fish using tree bark.

10. Dissatisfied with conventional mousetraps that, at best, maimed the unfortunate creatures, the environmental protection agency set out to design a trap that was not only safe but that also alerted the homeowner via a beeping mechanism that the trap had been released. This way, the rodent could be set free immediately rather than neglected for perhaps weeks.

11. The analogy of a computer being like the brain led to an entirely new understanding of the memory system as an information processing center and humans as active processors rather than mere respondents to environmental stimulation.

12. Mr. Sanders never had trouble keeping his eighth grade students in line but had difficulty disciplining his own children. Mr. Sanders thought about this problem and then developed a variety of techniques for home discipline based on his school experience.

13. When it came time to buy a new car, Mr. Finance used a plan similar to the plan he used when he bought his new house. As expected, the plan permitted him to buy the car at a low interest rate with no money down.

14. The peanut vendor at the ballpark constantly kept the fans entertained with his imitations of famous people selling peanuts, his humorous broadcasting of the game in pig-Latin, and his ability to "hit" a customer at 20 rows with a bag of peanuts tossed behind the back or through the legs.

15. Uncle John realizes that he is supposed to be at his nephew's birthday party tomorrow morning. He has no time to shop for a card or present, and in fact, has no money in his wallet. Using the idea of advertisers who provide customers with free meal coupons, Uncle John makes a card for his nephew. It contains a coupon entitling the bearer to one free day at Adventureland--hot dog lunch included-with Uncle John.

16. After the wedding ceremony everyone commented on how personal and well planned the service seemed given that the priest, who did not know the couple previously, was a last minute replacement for Father Weaver. 


\section{Appendix E}

\section{Post-Experiment Survey}

\section{ID \#}

For each question, please circle one answer.

1. What is your year in school?

Freshman Sophomore Junior Senior Graduate

2. What is your major?
Psychology
Other social science
Other

3. What is your approximate grade-point average?
Below $1.5 \quad 1.6$ to 2.0
2.1 to 2.5
2.6 to 3.0
3.1 to 3.5
3.6 to 4.0

4. On a scale of 1 to 5 , how motivated were you to perform well on this test?

\begin{tabular}{|c|c|c|c|c|}
\hline 1 & 2 & 3 & 4 & 5 \\
\hline $\begin{array}{l}\text { Not at all } \\
\text { Motivated }\end{array}$ & $\begin{array}{c}\text { Slightly } \\
\text { motivated }\end{array}$ & $\begin{array}{l}\text { Somewhat } \\
\text { motivated }\end{array}$ & $\begin{array}{c}\text { Very } \\
\text { motivated }\end{array}$ & \\
\hline
\end{tabular}

5. What materials did you rely on most during your study period?

$\begin{array}{lll}\text { The notes } & \begin{array}{l}\text { The notes } \\ \text { given to me }\end{array} & \begin{array}{l}\text { My summaries } \\ \text { or examples }\end{array}\end{array}$

6. Did you have any knowledge of the types of creativity described in the lecture before you saw the lecture (please circle one)?
Yes
No 